\title{
The Solubility of Phenylborate Compounds in Benzene
}

by

R. E. Eibling

Westinghouse Savannah River Company

Savannah River Site

Aiken, South Carolina 29808

MASTER Hol

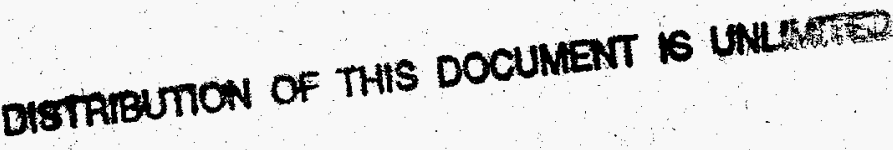

DOE Contract No. : DE-AC09-96SR18500

This paper was prepared in connection with work done under the above contract number with the U.S.

Department of Energy. By acceptance of this paper, the publisher and/or recipient acknowledges the U.S.

Government's right to retain a nonexclusive, royalty-free license in and to any copyright covering this paper, along with the right to reproduce and to authorize others to reproduce all or part of the copyrighted paper. 


\section{DISCLAIMER}

This report was prepared as an account of work sponsored by an agency of the United States Government. Neither the United States Government nor any agency thereof, nor any of their employees, makes any warranty, express or implied, or assumes any legal liability or responsibility for the accuracy, completeness, or usefulness of any information, apparatus, product, or process disclosed, or represents that its use would not infringe privately owned rights. Reference herein to any specific commercial product, process, or service by trade name, trademark, manufacturer, or otherwise does not necessarily constitute or imply its endorsement, recommendation, or favoring by the United States Government or any agency thereof. The views and opinions of authors expressed herein do not necessarily state or reflect those of the United States Government or any agency thereof.

This report has been reproduced directly from the best available copy.

Available to DOE and DOE contractors from the Office of Scientific and Technical Information, P.O. Box 62, Oak Ridge, TN 37831; prices available from (615) 576-8401.

Available to the public from the National Technical Information Service, U.S. Department of Commerce; 5285 Port Royal Road, Springfield, VA 22161. 


\section{DISCLAIMER}

Portions of this document may be illegible electronic image products. Images are produced from the best available original document. 
WSRC-TR-98-00129

\section{The Solubility of Phenylborate Compounds in Benzene}

Russell E. Eibling

Publication Date: $4-15-98$

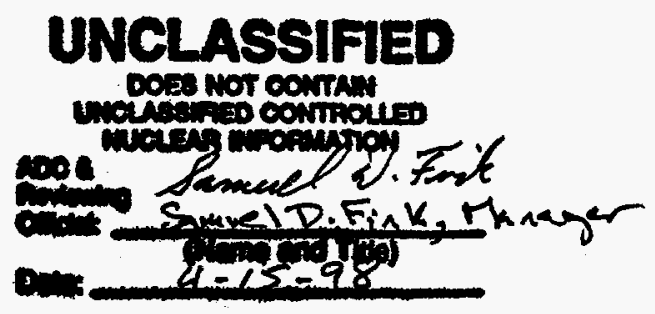

Westinghouse Savannah River Company

Savannah River Site

Aiken, SC 29808

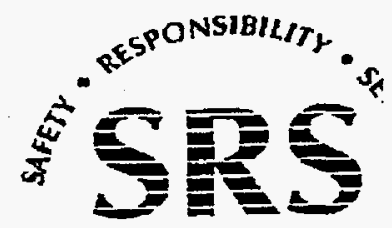

SAVANNAH RIVER S

PREPARED FOR THE U.S. DEPARTMENT OF ENERGY UNDER CONTRACT NO. DE-AC09-96SR18500 
WSRC-TR-98-00129 Rev. 0

Page 2 of 9

Author

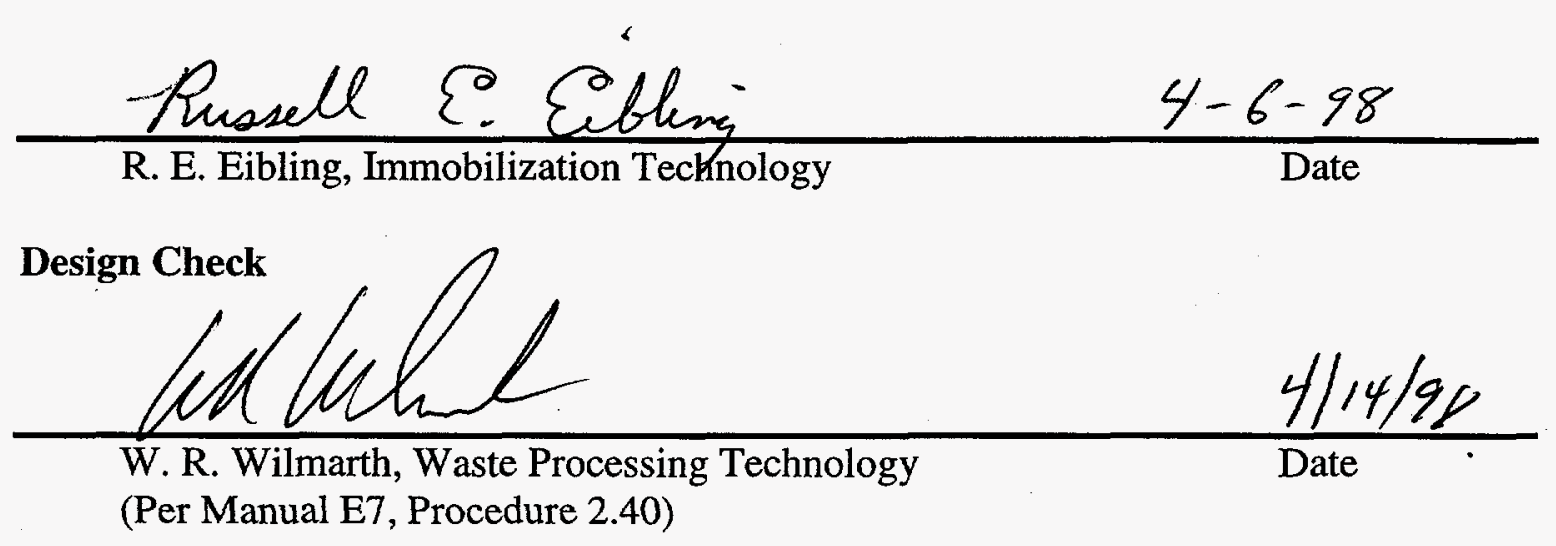

Approvals
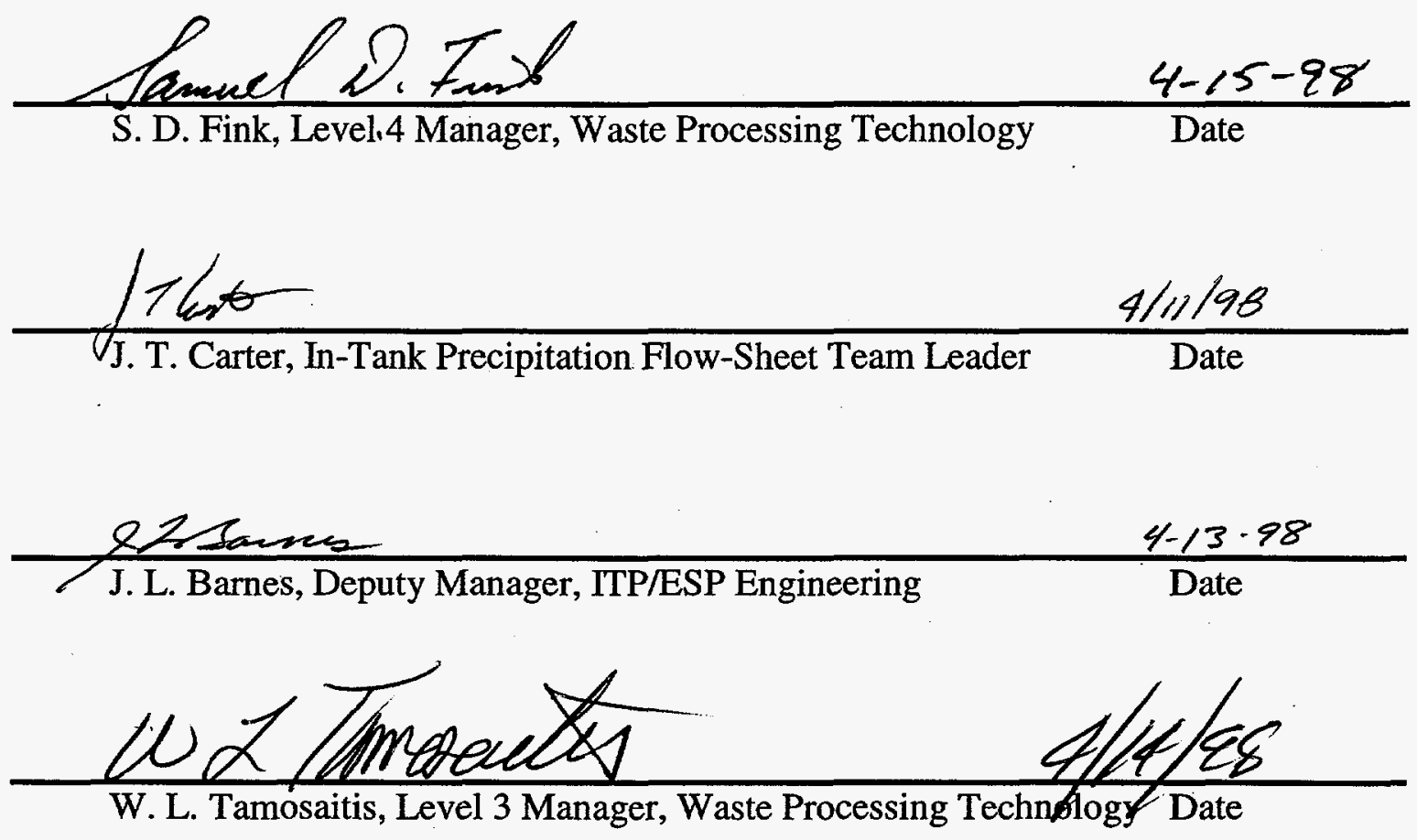
WSRC-TR-98-00129 Rev. 0

Page 3 of 9

\title{
Solubility of Phenylborate Compounds in Benzene
}

\author{
Russell E. Eibling \\ Westinghouse Savannah River Company \\ Savannah River Technology Center \\ Aiken, South Carolina 29808
}

\section{Summary and Recommendations}

The original goal of this scoping study was to determine if the solubility of sodium and potassium tetraphenylborates in benzene was sufficiently large to justify designing and performing kinetic studies on a benzene-phase catalytic reaction. Based upon the results of the scoping experiments:

- The solubility of sodium and potassium tetraphenylborate is less than or equal to $3 \mathrm{E}-6$ moles per liter of benzene.

- The solubility of triphenylborane in benzene when in contact with an alkaline aqueous phase is about 1.2E-5 moles per liter of benzene.

- The very low solubility of the tetraphenylborate salts and the triphenylborane product of the first step of the decomposition reaction would make monitoring the reaction infeasible by current analytical methods.

- Since the solubility of all of the phenylborates in aqueous alkaline solutions greatly exceeds that in benzene, a benzene phase reaction appears less likely. Future studies should focus on aqueous phase reactions or on interfacial reactions.

\section{Introduction}

The In-Tank Precipitation (ITP) process decontaminates high level waste salt solutions by precipitating radioactive cesium with tetraphenylborate anion. Excessive production of benzene occurred due to decomposition of soluble tetraphenylborate during the processing of the first batch of salt solution in ITP in 1995. The discovery of a higher than expected rate of decomposition of soluble sodium tetraphenylborate in Tank $48 \mathrm{H}$ during the ITP process generated several studies designed to elucidate the mechanism of the decomposition reactions. ${ }^{1,2}$ Research on identifying the catalytic species active in the decomposition of tetraphenylborate identified benzene as required for full activity of the catalyst. ${ }^{3,4}$ This report describes the results of a study to determine the solubility of phenylborate compounds in benzene. This scoping study fulfills a request from $P$. $L$. Rutland, "Solubility of Phenylborate Compounds," Technical Assistance Request \#HLETAR-98042, Rev. 0, March 5, 1998. 


\section{Background}

The initial proposed mechanism for the alkaline hydrolysis of tetraphenylborate anion involves an aqueous phase reaction of soluble tetraphenylborate with either a soluble homogeneous catalyst such as soluble $\mathrm{Cu}^{+2}$ or a heterogeneous catalyst. Studies on the copper-only alkaline hydrolysis reaction did not produce rates large enough to explain the Tank $48 \mathrm{H}$ occurrence. ${ }^{5}$ Studies to identify alternative catalysts demonstrated that palladium in the presence of the tetraphenylborate intermediates, diphenylmercury and benzene produced larger rates of reaction than copper for the test conditions. ${ }^{3,4}$ The apparent requirement that benzene be present suggested an alternative mechanism might involve a benzene phase reaction. As benzene accumulates in the tetraphenylborate slurry, testing suggests benzene will coat the insoluble tetraphenylborate solids and eventually form droplets. ${ }^{6}$ Within this benzene phase, dissolved tetraphenylborate could react with an organic-soluble catalyst (homogeneous catalyst) or with a supported heterogeneous catalyst. For such a mechanism to play a significant role, one would expect appreciable solubility in benzene for the tetraphenylborate compounds, sodium tetraphenylborate (NaTPB) and potassium tetraphenylborate (KTPB).

An organic phase could also assist the decomposition reaction by providing an environment that would favor the product of each step of the reaction. The favorable environment would increase the rate of the transition from the activated complex to the final products by stabilizing the products. Again, the solubility of the products in the reaction medium provides a measure of the desirability of the environment. Therefore, we require knowledge of the solubility of triphenylborane, diphenylborinic acid and phenylboronic acid in benzene to judge whether the environment might assist the reaction.

\section{Analytical Methods}

The solubility of the phenylborates in benzene was measured by high performance liquid chromatography (HPLC) using a method obtained from the Analytical Development Section (ADS). The method was installed on a Hewlett-Packard 1090 Series II HPLC with only minor modifications to match the instrument and available columns. Standards obtained from ADS were used to confirm method calibration before and after analysis of each set of samples. Compound identification was based upon retention time and confirmed by matching the peak's ultraviolet spectra with that obtained from the standard.

The primary difficulty in analyzing the sodium tetraphenylborate and potassium tetraphenylborate concentration in benzene involved overlap between a benzene peak and the tetraphenylborate peak. The use of alternative wavelengths for analytical measurements and calculations was considered; however, there were no wavelengths at which one absorbed and the other was transparent. Using the high volatility of benzene eliminated the interference. A portion of the benzene sample was evaporated to dryness under a nitrogen purge and the residual material dissolved in acetonitrile. Varying the 
volume of the acetonitrile allowed concentration or dilution of the sample as needed for the analysis.

\section{Results}

The decomposition of tetraphenylborate in alkaline aqueous slurry consists of a series of reaction steps that consume water and produce benzene and one of the intermediates, triphenylborane (3PB), diphenylborinic acid (2PB), phenylboronic acid (1PB), and the final product, borate anion. The solubility of water in benzene from 273 to $343^{\circ}$ Kelvin can be calculated using the following formula. ${ }^{7}$

$$
\mathrm{G}=-5.6667+6.3536 \times 10^{-2} \mathrm{~T}-2.4024 \times 10^{-4} \mathrm{~T}^{2}+3.0572 \times 10^{-7} \mathrm{~T}^{3}
$$

with $T$ in degrees Kelvin and $G$ as grams of water/100grams benzene

Figure 1 plots the resulting curve and allows estimates of the amount of water present under expected operating conditions.

Figure 1

Solubility of $W$ ater in Benzene

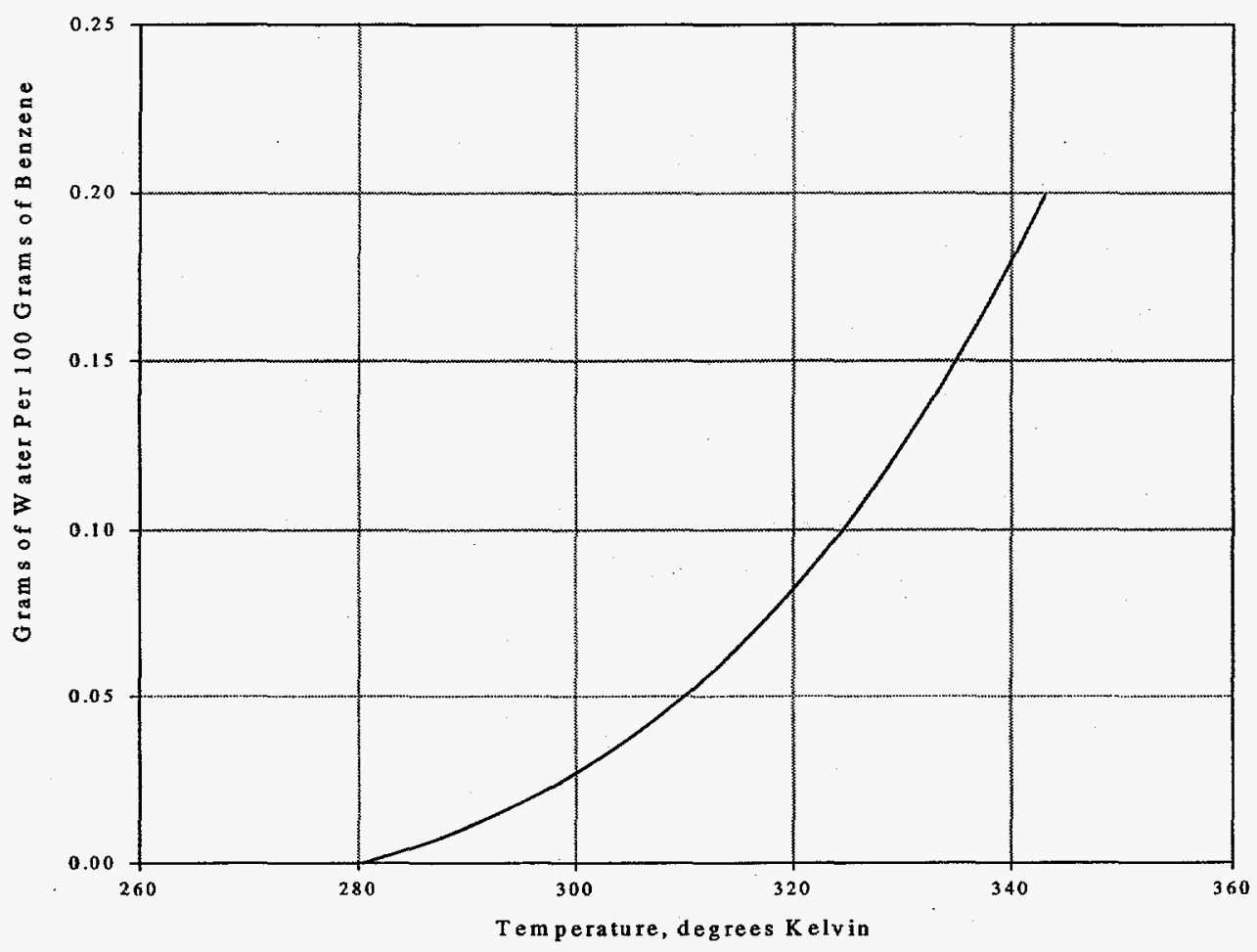


The displayed curve holds for water in benzene. Since the additional dissolved salts in the alkaline system provide a highly ionic environment, water solubility in an adjacent benzene phase would decrease.

Scoping tests measured the solubility of the phenylborate compounds by placing them in contact with benzene or water-saturated benzene and analyzing the benzene by HPLC. The potassium tetraphenylborate came from D. D. Walker. The test used sodium tetraphenylborate (ACS Reagent grade) obtained from Aldrich Chemical Company. The triphenylborane came from a sodium hydroxide adduct solution obtained from Aldrich Chemical Company. The diphenylborinic acid was the ethanolamine complex obtained from Aldrich Chemical Company. All tests occurred at ambient temperatures.

The most soluble of the compounds was the ethanolamine complex of diphenylborinic acid at 0.003 moles per liter of benzene. Table 1 lists the results for the other compounds. Triphenylborane was expected to be more soluble based upon its high aromatic character and probable low polarity compared to the ionic tetraphenylborates and the hydroxyl-substituted acids. The measured solubility probably reflects the high stability of the hydroxide adduct and its high affinity for water. The values for sodium and potassium tetraphenylborate only provide estimates since the very small signals occurred at the limit of measurement and could possibly reflect small, insoluble particles in the benzene phase.

Table 1

Results of Solubility Experiments

\begin{tabular}{|c|c|c|c|c|c|c|c|}
\hline Expt & Compound & Solvent* & NaTPB & KTPB & 2PB & 3PB & Notes** \\
\hline & & & molar & molar & molar & molar & \\
\hline 1 & NaTPB & Benzene & $<3 \mathrm{E}-6$ & & & & \\
\hline 2 & KTPB & Benzene & & $3 \mathrm{E}-6$ & & & \\
\hline 3 & NaTPB & Ben/Wat & $<3 \mathrm{E}-6$ & & & & \\
\hline 4 & NaTPB & Ben/Salt & $<3 \mathrm{E}-6$ & & & & \\
\hline 5 & KTPB & Ben/Wat & & $<3 \mathrm{E}-6$ & & & \\
\hline 6 & KTPB & Ben/Salt & & $<3 \mathrm{E}-6$ & & & \\
\hline 7 & $2 \mathrm{~PB}$ & Benzene & & & $2.9 \mathrm{E}-3$ & & \\
\hline $7 \mathrm{~A}$ & $2 \mathrm{~PB}$ & Benzene & & & $2.9 \mathrm{E}-3$ & & $\mathrm{~A}$ \\
\hline 8 & 3PB & Ben/Salt & & & & $<4 \mathrm{E}-5$ & \\
\hline $8 \mathrm{~A}$ & $3 \mathrm{~PB}$ & Ben/Salt & & & & $1.2 \mathrm{E}-5$ & $\mathrm{~B}$ \\
\hline
\end{tabular}

* Ben/Wat is water saturated benzene, Ben/Salt is alkaline water in contact with benzene.

** Notes

A Experiment 7 reanalyzed after two weeks.

B Experiment 8 analyzed after two weeks with a different dilution factor also observed phenol and 2-phenylphenol. 
Phenylboronic acid solubility in benzene was not measured since the solubility exists in the literature. ${ }^{8}$ Based upon the information in the literature the solubility in benzene at $20^{\circ} \mathrm{C}$ is $0.086 \mathrm{M}$. Despite the expected high polarity of phenylboronic acid, the solubility in benzene may reflect the behavior in reaction (1), which generates a stable anhydride with higher solubility in benzene.

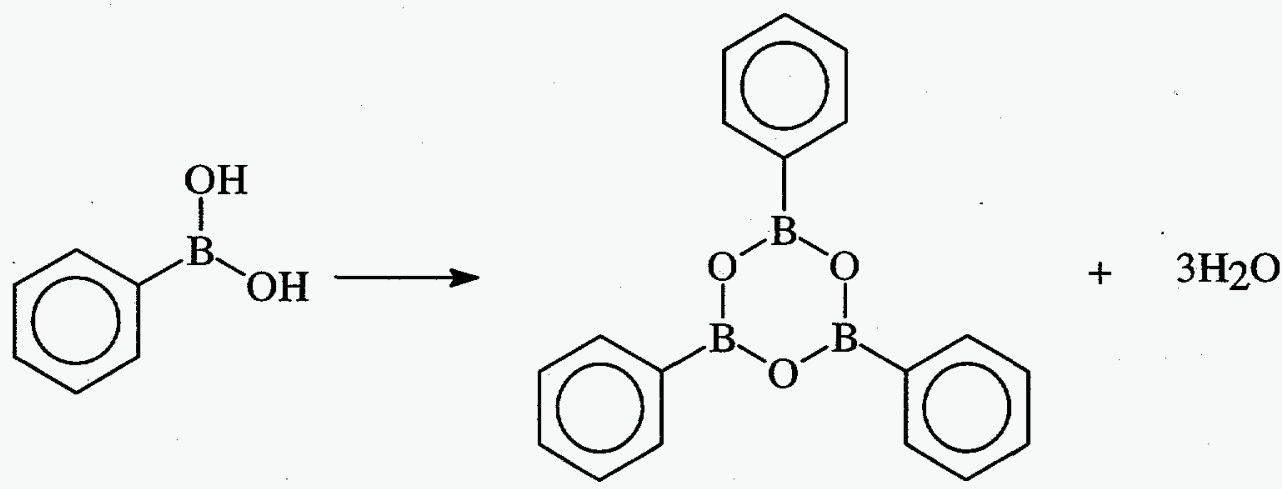

The conversion to the anhydride, triphenylboroxine, is facile and can occur due to exposure of the compound to low humidity air or by the addition of heat. Conversion back to the acid can occur by the addition of water.

The solubility of phenylboronic acid and of its anhydride does increase with temperature. For phenylboronic acid, the solubility nearly triples by increasing the temperature to $40^{\circ} \mathrm{C}$. Some increase in the solubility of the tetraphenylborates, and of triphenylborane and diphenylborinic acid with increasing temperature, would likely occur. However, the increase in solubility does not appear sufficient to make the soluble organic phase catalysis likely. Previous research on the alkaline aqueous solubility of these compounds showed much higher solubility indicating that any reaction in the aqueous phase would tend to dominate the observed disappearance of tetraphenylborate., ${ }^{9,10}$

\section{Conclusions}

This scoping study sought to determine if the solubility of sodium and potassium tetraphenylborates was sufficiently large to justify designing and performing kinetic studies on a benzene-phase catalytic reaction. The results of the scoping experiments, below, suggest a low probability for a benzene phase reaction.

- The solubility of sodium and potassium tetraphenylborate is less than or equal to $3 \mathrm{E}-6$ moles per liter of benzene.

- The solubility of triphenylborane in benzene when in contact with an alkaline aqueous phase is about 1.2E-5 moles per liter of benzene.

- The very low solubility of the tetraphenylborate salts or the triphenylborane product of the first step of the decomposition reaction would make monitoring the reaction infeasible by current analytical methods. 
- Since the solubility of all of the phenylborates in aqueous alkaline solutions greatly exceeds that in benzene, a benzene phase reaction appears less likely. Future studies should focus on aqueous phase reactions or on interfacial reactions.

If future modeling studies need accurate concentrations in benzene, additional work on these compounds should include temperature as a control variable and measure the partitioning coefficient between the expected aqueous compositions and the benzene phase. The solubility values in this report do not rule out the possibility of a reaction mechanism that occurs at the interface between the benzene and aqueous phases due to an interfacially-supported catalyst.

\section{Quality Assurance}

Laboratory notebook WSRC-NB-96-721 contains the details of the experiments, calculations performed and the experimental results.

\section{References}

1. Department of Energy Implementation Plan for Defense Nuclear Facilities Safety Board Recommendation 96-1 to the Secretary of Energy, In-Tank Precipitation Facility at the Savannah River Site", A. Lee Watkins, DNFSB 96-1 Implementation Plan, Rev. 0, October 21,1996.

2. D. D. Walker, M. J. Barnes, C. L. Crawford, R. F. Swingle, R. A. Peterson, M. S. Hay, and S. D. Fink, "Decomposition of Tetraphenylborate in Tank 48-H (U)", WSRC-TR-96-0113, May 10, 1996.

3. M. J. Barnes and R. A. Peterson, "Sodium Tetraphenylborate Catalyst Identification: Phase A Statistical Design Studies (U)", WSRC-TR-97-0210, Rev. 0, July 22, 1997.

4. M. J. Barnes and R. A. Peterson, "Sodium Tetraphenylborate Catalyst Identification: Phase B and C Statistical Design Studies (U)", WSRC-TR-970230, Rev. 0, August 13, 1997.

5. M. J. Barnes and T. B. Edwards, "Copper Catalyzed Sodium Tetraphenylborate Decomposition Kinetic Studies (U)”, WSRC-TR-96-0351, Rev. 0, November 7, 1996.

6. L. O. Dworjanyn, "Benzene Retention in TPB Slurry - Status Report (U)," WSRC-RP-97-217, March 26, 1997.

7. D. G. Shaw, Volume editor, Solubility Data Series, Volume 37, Hydrocarbons with Water and Seawater, Part 1: Hydrocarbons $C_{5}$ to $C_{7}$, p.73, Pergamon Press, New York (1989). 
8. R. M. Washburn, E. Levens, C. F. Albright, F. A. Billig and E. S. Cernak, "Preparation, Properties, and Uses of Benzeneboronic Acid", in Metal-Organic Compounds, p. 102-127, American Chemical Society, Washington, D. C. (1959).

9. D. J. McCabe, "Cesium, Potassium and Sodium Tetraphenylborate Solubility in Salt Solution (U)”, WSRC-RP-96-0384, Rev. 0, December 12, 1996.

10. W. R. Wilmarth, "Solubility Studies of Tetraphenylborate Intermediates", WSRC-RP-97-0094, April 9, 1997. 